\title{
Research on Motivation of Computer Science Students in Financial College
}

\author{
Jun Rao*, Fang Wang \\ Tianjin University of Finance and Economics, Tianjin, China \\ rjnew@sina.com
}

Keywords: Learning Motivation, Computer Science Students, Financial College, Questionnaire.

Abstract. This paper discussed learning motivation differences among computer science students in financial college. To present it, 264 computer science students were surveyed. The questionnaire showed the situation of these students' learning motivation, The paper mainly adopts Cronbach $\alpha$, frequency analysis, t-test and one-way ANOVA methods, etc. The results indicated that the gender, grade differences of learning motivation of students are significant. Finally the paper concentrates on a series of factors which result in the lack of motivation of students, and finds out some strategies and methods, which aim at stimulating students' interest of learning and improve the teaching job.

\section{Introduction}

The phenomenon that learning motivation of students is not strong is associated with the increase enrollment of the university entrance exams in recent years[1,2]. However, the existing researches just put forward this phenomenon and lack deep analysis of learning motivation and corresponding methods to deal with it[3].

The paper presents an investigation on computer science students in financial college, then shows the current situation of students' learning motivation, finally concentrates on a series of factors which result in the lack of motivation of students[4].

These results are useful to find out set of strategies and methods for stimulating students' interest of learning and improve the teaching job.

\section{Sample and Survey tool}

1. Sample

Table 1. Sample specific distribution

\begin{tabular}{cccc}
\hline type & value & $\mathrm{N}$ & percentage \\
\hline Grade & freshman & 46 & $17 \%$ \\
& sophomore & 89 & $34 \%$ \\
& junior & 92 & $35 \%$ \\
& senior & 37 & $14 \%$ \\
\hline \multirow{2}{*}{ Gender } & male & 105 & $40 \%$ \\
& female & 159 & $60 \%$ \\
\hline
\end{tabular}

The investigation objects are the students of College in Tianjin university of Finance and Economics, including all the students from freshman to seniors. The questionnaires provided add up to 280 , and got back 264 . The percentage of recovery is $94 \%$, and the effective rate is $100 \%$. Sample specific distribution situation is shown in Table 1 .

2. Survey tool 
The surrey tool of this research is the questionnaire revised according the questionnaire of students' learning motivation, which edited by Huang Xi-ting[5], and the questionnaire includes two parts:

(1) The basic personal information of students. It is concluded of gender, grades and majors.

(2) The learning motivation questionnaire of students. It consists of 29 items, and includes 6 dimensions.

The scores of Questionnaire include 5 levels, which marks with 5, 4, 3, 2 and 1. The higher the score means the more strong motivation, and vice versa.

All data is input by the researchers using the Excel 2003 of Microsoft Company into the computer and verified. Then imports from Excel data file to SPSS 10.0. The paper mainly adopts Cronbach $\alpha$, frequency analysis, t-test and one-way ANOVA methods, etc.

\section{Survey results and analysis}

1. Index of observation

(1) The general situation of learning motivation of students.

(2) The gender, grade differences of learning motivation of students.

2. Survey results

2.1 The general situation

Table 2. Mean of all dimensions of learning motivation

\begin{tabular}{ccc}
\hline dimensions & mean & Std. Deviation \\
\hline Seeking knowledge & 4.2022 & 0.5583 \\
Social orientation & 4.0114 & 0.7170 \\
materialistic & 3.9136 & 0.6157 \\
Small groups orientation & 3.7727 & 0.7508 \\
Personal achievement & 3.5997 & 0.8093 \\
Fear of failure & 3.3930 & 0.8354 \\
\hline
\end{tabular}

As is shown in the Table 2, the mean of the 6 dimensions of these students' learning motivations, which are listed from high to low, are seeking knowledge, social orientation, materialistic, small groups orientation, personal achievement, fear of failure[6,7]. According to the mean, the first 2 motivations are obviously stronger, the mean of which are larger than 4 , the later 4 motivations are weaker, the mean of which are all smaller (The whole distance is 5).

According to Table 3 we can know the each item's situation of the students' learning motivations. From the top 5 items, we know that, apart from seeking knowledge, serving others and the society while realizing self-worth is also important in the prime motivation of the students to learning (rank 5 in the survey). From the last 5 items, we know that, currently the sense of collective honor has declined in the learning motivations of the students major in computer science; the class cohesion has been weakened.

Table 3. Each item's mean of the motivations (only the former 5 items and the later 5 items)

\begin{tabular}{|c|c|c|c|c|}
\hline item & Mean & S.D & topic & dimensions \\
\hline Q6 & 4.49 & 0.78 & Learning for the success of the career in future. & Seeking knowledge \\
\hline Q29 & 4.46 & 0.76 & Urgent need to learn new knowledge. & Seeking knowledge \\
\hline Q3 & 4.39 & 0.80 & $\begin{array}{l}\text { Professional learning is useful to succeed and develop } \\
\text { potential and value. }\end{array}$ & Seeking knowledge \\
\hline
\end{tabular}




\begin{tabular}{|c|c|c|c|c|}
\hline Q4 & 4.37 & 0.83 & Be interested in learning contents or learning itself. & Seeking knowledge \\
\hline Q11 & 4.34 & 0.77 & $\begin{array}{l}\text { serving others and the society while realizing } \\
\text { self-worth. }\end{array}$ & Social orientation \\
\hline$\cdots$ & & & $\cdots$ & $\cdots$ \\
\hline Q8 & 3.35 & 1.16 & $\begin{array}{l}\text { Learning is to maintain the school' s honor, winning } \\
\text { glory for the school? }\end{array}$ & Social orientation \\
\hline Q21 & 3.34 & 1.24 & Worried that you can not graduate and get the diploma. & Fear of failure \\
\hline Q18 & 3.31 & 1.14 & Worried about the competition between classmates. & Fear of failure \\
\hline Q27 & 3.02 & 1.10 & Learning for best friend. & Small groups orientation \\
\hline Q7 & 2.82 & 1.09 & Learning for raise your status in class & materialistic \\
\hline
\end{tabular}

2.2 The gender differences

Table 4. Gender differences of the motivations

\begin{tabular}{cccccc}
\hline dimensions & gender & $\mathrm{N}$ & mean & Std. Deviation & $\mathrm{t}$ value \\
\hline \multirow{2}{*}{ Seeking knowledge } & male & 105 & 4.0905 & 0.6332 & $-2.672 * *$ \\
& female & 159 & 4.2759 & 0.491 & \\
\cline { 2 - 6 } Social orientation & male & 105 & 3.8971 & 0.754 & $-2.117 *$ \\
& female & 159 & 4.0868 & 0.6834 & \\
\cline { 2 - 6 } materialistic & male & 105 & 3.8895 & 0.6742 & -0.516 \\
Fear of failure & female & 159 & 3.9296 & 0.5755 & \\
\cline { 2 - 6 } & male & 105 & 3.3167 & 0.9362 & -1.207 \\
\cline { 2 - 6 } Personal achievement & female & 159 & 3.4434 & 0.7604 & \\
\cline { 2 - 6 } Small groups & male & 105 & 3.6032 & 0.7819 & 0.056 \\
\cline { 2 - 6 } orientation & female & 159 & 3.5975 & 0.8294 & -0.692 \\
\hline
\end{tabular}

Note: * means significant difference $(\mathrm{p}<0.05), * *$ means very significant difference $(\mathrm{p}<0.01)$.

Table 4 shows that there exists very significant differences among students of different genders in seeking knowledge. Among the students major in computer science, for boys, it appears significantly lower than girls in other aspects. Meanwhile in personal achievements, they are closer to each other.

\subsection{The grade difference}

(1) The grade differences and analysis of boys

Table 5 shows that there are significant differences between the boys in freshman and those in other grades in seeking knowledge. In motivation of materialistic, the level of freshman is significantly lower than the level of other grades' students.

In small groups orientation sophomore and junior are significantly different from freshman and senior. 
Table 5. Significant grade differences of boys' motivation

\begin{tabular}{cccc}
\hline dimensions & (I) grade & (J) grade & $\mathrm{p}$ \\
\hline Seeking knowledge & freshman & senior & 0.02 \\
& & junior & 0.039 \\
& & sophomore & 0.009 \\
\hline materialistic & freshman & senior & 0.048 \\
& & junior & 0.005 \\
& & sophomore & 0.014 \\
\hline Small groups orientation & junior & freshman & 0.009 \\
& & senior & 0.005 \\
\hline Small groups orientation & sophomore & freshman & 0.045 \\
& & senior & 0.034 \\
\hline
\end{tabular}

Note: $\mathrm{p}<0.05$ significant, $\mathrm{p}<0.01$ very significant.

(2) The grade differences and analysis of girls

From table 6, we can see that the scores of seeking knowledge for girls rises with the growth of grade. In social orientation, the sophomore are significantly different from senior. In the fear of failure freshman and senior are significantly different.

Table 6. Significant grade differences of girls' motivation

\begin{tabular}{cccc}
\hline dimensions & $(\mathrm{I})$ grade & $(\mathrm{J})$ grade & $\mathrm{p}$ \\
\hline & & senior & 0.023 \\
Seeking knowledge & freshman & junior & 0.006 \\
& & sophomore & 0.016 \\
\cline { 2 - 4 } Social orientation & sophomore & senior & 0.046 \\
Fear of failure & freshman & senior & 0.011 \\
\hline
\end{tabular}

Note: $\mathrm{p}<0.05$ significant, $\mathrm{p}<0.01$ very significant.

\section{Summary}

Through the investigation and analysis, we can conclude that the basic conclusion:

(1) The mean of different dimension of students' learning motivation from high to low is as follows: seeking knowledge, the social orientation, material and enterprising, small groups orientation, personal achievement, the fear of failure.

(2) According to the mean of different question of students' learning motivation, we know that students have stronger individualism orientation, and weaker sense of organization.

(3) The gender differences of students are significant in social orientation, and it is more significant in seeking knowledge.

(4) The grade differences of boys are significant in seeking knowledge, material and enterprising, small groups orientation.

(5) The grade differences of girls are significant in seeking knowledge, the social orientation, the fear of failure.

Based on the above research, there are some suggestions to improve learning motivation of students $[8,9,10]$ : 
(1) To strengthen the education and guidance to team spirit.

(2) To correct study manner.

(3) To establish clear learning objectives.

(4) To improve their teaching methods, teaching students according to their aptitude.

(5) To adjust the courses and strengthen the link of practice and teaching.

(6) To strengthen the emotional communication between teachers and students.

\section{Acknowledgement}

This research was financially supported by the the Teaching Research Funds for Tianjin University of Finance and Economics (Grant NO.JC2013-03).

\section{References}

[1] Bin Jiancheng, Zhan Huaxiu: submitted to Journal of The theory and practice of finance and economics (2013)

[2] WangLei: submitted to Journal of Hainan financial (2008)

[3] Zhu Mengnan, LiuLin: submitted to Journal of The study of finance and trade (2010)

[4] Chen Jinmei, Xu Zhenling: submitted to Journal of The economist (2012)

[5] Wang Shihua, He Fan: submitted to Journal of The world economy (2007)

[6] JL Allen, LD Walker, DA Schroeder, Attributions and attribution- behavior relations: The effect of level of cognitive development. Journal of Personality and Social Psychology, Vol 52(6), 1099-1109,1987.

[7] Bernard Weiner, Intrapersonal and Interpersonal Theories of Motivation from an Attributional Perspective. Educational Psychology Review, Vol.12, No.1. 1-14, 2000. 